\title{
Short Review on Treatment of Superficial Bladder Cancer (Ta, Tis, T1)
}

\author{
Phalguni Gupta* \\ Department of Radiotherapy, N R S Medical College, Kolkata India
}

Submission: May 14, 2019; Published: May 28, 2019

"Correspondence Author: Phalguni Gupta, Professor, Department of Radiotherapy, N R S Medical College, Kolkata India

\section{Mini Review}

At presentation, $70 \%$ of patients with bladder cancer have superficial disease, out of which, approximately $15 \%$ to $20 \%$ will progress to stage $\mathrm{T} 2$ disease or greater over time. Following initial therapy, $50 \%$ to $70 \%$ of those presenting with Ta or T1 disease will have a recurrence. Low-grade tumors (grade I or II) and low-stage (Ta) disease tend to have a lower recurrence rate at about $50 \%$ and a $5 \%$ progression rate, whereas highrisk disease (grade III, T1 associated with CIS, and multifocal disease) has a $70 \%$ recurrence rate and a $30 \%$ progression rate to stage $\mathrm{T} 2$ disease or greater disease. Less than $5 \%$ of patients with superficial bladder cancer will develop metastatic disease without developing evidence of muscularis propria invasion (stage T2 disease or greater) of the primary lesion.

Patients who are at significant risk for development of progressive disease or recurrent disease following TURBT are generally considered candidates for adjuvant intravesical drug therapy, which practically would include those with multifocal CIS, CIS associated with Ta or T1 tumors, any grade III tumor, multifocal tumors, and those whose tumors rapidly recur following TURBT of the initial bladder tumor.

A number of drugs have been used intravesical, including Bacillus Calmette-Guerin (BCG), interferon and BCG, thiotepa, mitomycin $\mathrm{C}$, doxorubicin, and gemcitabine. Complications generally include frequency, dysuria, and irritative voiding symptoms. Over the long term, bladder contracture may occur with these agents. Other complications, which are specific for each drug, are as follows: BCG administration may result in fever, joint pain, granulomatous prostatitis, sinus formation, disseminated tuberculosis, and death; thiotepa may cause myelosuppression; mitomycin C may cause skin desquamation and rash; and doxorubicin may cause gastrointestinal upset and allergic reactions. The proposed benefit of intravesical chemotherapy is to lessen the rate of recurrences and reduce the incidence of progression. Unfortunately, it cannot be clearly stated that any of these drugs accomplish these goals over the long term. Many studies have demonstrated that over the short term there is a reduction in the recurrence rate of superficial tumors. Unfortunately, in many of these studies the follow-up is less than 2 years.

Number of studies has compared one intravesical chemotherapeutic agent with another. For the most part, BCG in these comparisons has a slight advantage in reducing recurrences [1]. However, when the follow-up is more than 5 years, it appears that there is minimal overall effect in reducing the recurrence rate when compared with no treatment. Approximately $70 \%$ of patients with high-grade disease will experience recurrence whether or not they are treated with intravesical therapy. Moreover, there is no well-documented evidence that the use of these agents prevents disease progression, that is, from stage $\mathrm{Ta} / \mathrm{T} 1$ disease to stage T2 or greater disease. Indeed, about one third of patients who are at high risk for disease progression (those with grade III, T1 disease) will progress to stage T2 or greater disease whether or not they are treated with BCG [2]. One third of patients at 5 years who have disease progression and undergo a Cystectomy, die of metastatic disease. Thus, approximately $15 \%$ of patients with superficial disease at high risk for disease progression (CIS with associated Ta or T1 disease, rapidly recurrent disease, and/or grade III disease), irrespective of treatment modality, will die of their disease.

If definitive therapy (cystectomy) is performed when the disease is found to progress into the muscularis propria (T2 or greater), there is no difference in cure rate when these patients are compared with those who present with $\mathrm{T} 2$ or greater disease primarily. These statistics have encouraged some to perform a pre-emptive cystectomy in those patients at high risk for progression before muscularis propria invasion is documented. Ten-year cancer-specific survivals of $80 \%$ are given as justification for this approach as compared with $50 \%$ in 


\section{Cancer Therapy \& Oncology International Journal}

patients in whom the cystectomy is performed when the disease progresses to involve the muscularis propria. Unfortunately, this approach subjects approximately two thirds of these patients who are included in the $80 \%$ cancer-specific survival figure to a needless cystectomy, making it questionable as to whether there is in fact any survival advantage whatsoever.

\section{References}

1. Shelley MD, Court JB, Kynaston H, Wilt TJ, Coles B, et al. (2003) Intravesical bacillus Calmette-Guerin versus mitomycin $\mathrm{C}$ for $\mathrm{Ta}$ and T1 bladder cancer Cochrane Database Syst Rev (3): CD003231.

2. Shahin O, Thalmann GN, Rentsch C, et al. (2003) A retrospective analysis of 153 patients treated with or without intravesical bacillus Calmette-Guerin for primary state T1 grade 3 bladder cancer: recurrence, progression and survival. J Urol 169(1): 96.

\section{Your next submission with Juniper Publishers will reach you the below assets}

- Quality Editorial service

- Swift Peer Review

- Reprints availability

- E-prints Service

- Manuscript Podcast for convenient understanding

- Global attainment for your research

- Manuscript accessibility in different formats ( Pdf, E-pub, Full Text, Audio)

- Unceasing customer service

Track the below URL for one-step submission https://juniperpublishers.com/online-submission.php 